\title{
Association Between US Administration Endorsement of Hydroxychloroquine for COVID-19 and Outpatient Prescribing
}

$\mathrm{J}$ Gen Intern Med 35(9):2826-8

DOI: $10.1007 / \mathrm{s} 11606-020-05938-4$

(c) Society of General Internal Medicine 2020

\section{BACKGROUND}

Currently, there are no proven effective therapies for the treatment or prevention of coronavirus disease 2019 (COVID-19). On March 19, 2020, hydroxychloroquine was publicly endorsed as a treatment for COVID-19 during a US Presidential press briefing. ${ }^{1}$ This recommendation was based only on limited pre-clinical studies, media reports, and a small non-randomized study without clinical or safety outcomes. ${ }^{2,3}$ Hydroxychloroquine is currently indicated for the treatment of uncomplicated malaria, rheumatoid arthritis, and systemic lupus erythematosus. Given that hydroxychloroquine is not currently approved or licensed by the US Food and Drug Administration for the treatment of COVID-19, it is unknown whether the Administration's endorsement of this medication affected prescribing practice.

\section{METHODS}

This analysis included outpatient prescription data on hydroxychloroquine prescribing between January 1 and April 15 of 2019 and 2020, derived from the electronic health records of patients at the University of Pennsylvania Health System and the Yale New Haven Health System. The US Presidential press conference endorsing hydroxychloroquine as a treatment for COVID-19 occurred on March 19, $2020 .{ }^{1}$ We investigated the number of outpatient prescriptions per week in the period of 9 weeks prior to and 4 weeks after the announcement. To control for possible seasonal trends, we analyzed the same time period in 2019. We used a difference in differences (DID) approach, estimated using a Poisson generalized linear model, to estimate multiplicative changes in the mean weekly number of prescriptions before and after March 19 in 2019 and 2020, as well as the multiplicative difference in the pre- to post-March 19 change, comparing the 2 years. This "difference in differences" represents the excess increase observed after the Presidential announcement

Received May 11, 2020

Accepted May 19, 2020

Published online June 15, 2020 in 2020 after accounting for seasonal trends based on the change observed in 2019. Analyses were conducted using R, version 3.6.3. The Institutional Review Board of both the University of Pennsylvania and Yale determined that this study did not constitute human subjects research as it uses only de-identified, aggregate data, and therefore did not require review.

\section{RESULTS}

Between January 1 and April 15, a total of 3280 and 5301 new prescriptions for hydroxychloroquine were identified in 2019 and 2020, respectively. Average weekly hydroxychloroquine prescribing increased substantially in the 4-week period after the announcement compared with the 9-week period prior (Fig. 1). In 2019, no change was observed in the mean number of prescriptions over the same period (percent difference $=$ $0.8 \%$ [95\% CI, -6.4 to $8.7 \%$ ], $p=0.827$ ) (Table 1). In comparison, in 2020, the mean number of prescriptions increased by $127 \%$, an excess increase of $125 \%$ (DID 95\% CI, 105.9 to $147.3 \%, p<0.001)$ relative to 2019 .

\section{DISCUSSION}

The US Administration's endorsement of hydroxychloroquine as a treatment for COVID-19 was associated with an abrupt increase in the rate of prescriptions for hydroxychloroquine. Given growing public interest in identifying safe and effective therapies for COVID-19, ${ }^{4}$ the US Administration's response to emerging data and its impact on drug prescribing patterns is important. Preliminary studies to date featuring hydroxychloroquine in combination with adjunctive agents for severe COVID-19 report it does not appear effective and may even be harmful. ${ }^{5}$ Indeed, off-label hydroxychloroquine prescribing is expected to contribute to supply chain shortages for approved chronic use during the pandemic. ${ }^{2}$ Furthermore, the issuance of the FDA's Emergency Use Authorization for hydroxychloroquine, which permits distribution of the drug from the national stockpile for the treatment of hospitalized patients with COVID-19, was widely misinterpreted as an FDA approval for this indication. ${ }^{4}$

This study suggests that Presidential endorsements can influence prescription practices, even in the absence of high- 


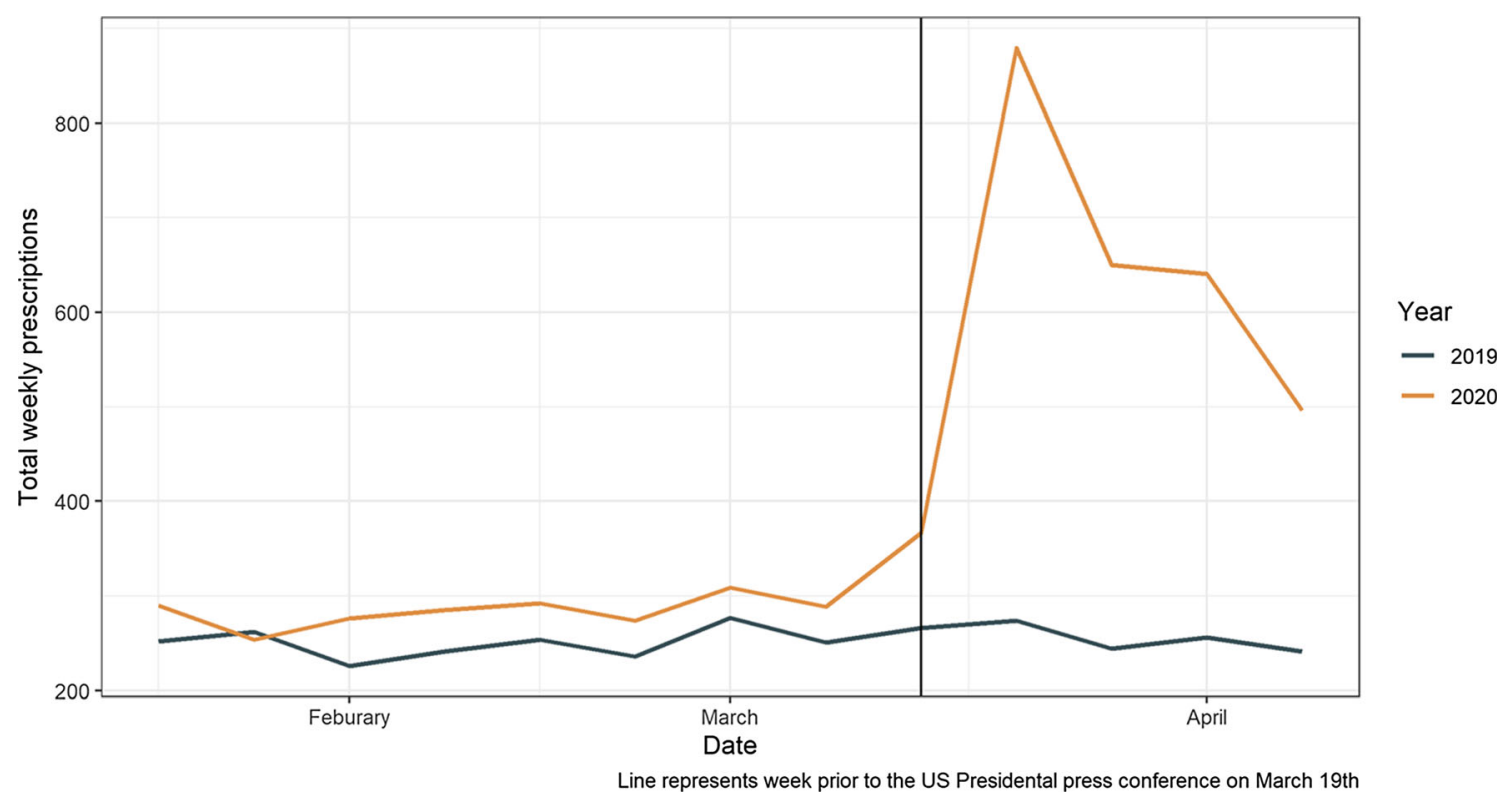

Figure 1 Trends in hydroxychloroquine prescribing before and after US administration endorsement.

Table 1 Difference in Differences Analysis: Change in Average Weekly Hydroxychloroquine Prescriptions Before and After US Administration Endorsement

\begin{tabular}{|c|c|c|c|c|c|c|c|}
\hline Years & $\begin{array}{l}\text { Mean } \\
\text { pre-March } 19\end{array}$ & $95 \% \mathrm{CI}$ & $\begin{array}{l}\text { Mean } \\
\text { post-March } 19\end{array}$ & $95 \% \mathrm{CI}$ & Percent change & $95 \% \mathrm{CI}$ & $p$ value \\
\hline $\begin{array}{l}2019 \\
2020 \\
\text { Difference in differences }\end{array}$ & $\begin{array}{l}251.7 \\
292.9\end{array}$ & $\begin{array}{l}(241.5,262.2) \\
(281.9,304.3)\end{array}$ & $\begin{array}{l}253.7 \\
666.2\end{array}$ & $\begin{array}{l}(238.6,269.9) \\
(641.4,692)\end{array}$ & $\begin{array}{l}0.80 \% \\
127.5 \% \\
125.6 \%\end{array}$ & $\begin{array}{l}(-6.4 \%, 8.6 \%) \\
(115.6 \%, 140.1 \%) \\
(105.9 \%, 147.3 \%)\end{array}$ & $\begin{array}{l}0.827 \\
<0.001 \\
<0.001\end{array}$ \\
\hline
\end{tabular}

quality evidence or US FDA approval for the given indication. Limitations include the indication for hydroxychloroquine treatment (COVID-19, lupus, or rheumatoid arthritis) or other clinical information on patients receiving treatment was not ascertained; and other factors, including the release of positive results from a preprinted study on March $16,2020,{ }^{3}$ as well as more patients being diagnosed with COVID-19 during this period, may have contributed to the observed trends. Strengths of this study include the use of the difference in differences design to account for temporal trends in prescribing, which were uncontrolled for in a prior report published in the lay press. ${ }^{6}$ Further studies will be needed to determine the effect of increased hydroxychloroquine use on patient outcomes.

James J. Harrigan, MD, PharmD ${ }^{1}$

Rebecca A. Hubbard, $P h D^{2}$

Sunil Thomas, M.B.A./T.M ${ }^{3}$

Ralph J. Riello, PharmD ${ }^{4}$

Erin Bange, $M D^{5}$

Mira Mamtani, MD, MSEd ${ }^{1}$

Ronac Mamtani, MD, MSCE ${ }^{5}$

${ }^{1}$ Hospital of the University of Pennsylvania,

Philadelphia, PA, USA

${ }^{2}$ Department of Biostatistics, Epidemiology and Informatics, Perelman School of Medicine,
University of Pennsylvania,

Philadelphia, PA, USA

${ }^{3}$ Penn Medicine Information Services, Data Analytics Center,

Philadelphia, PA, USA

${ }^{4}$ Division of Pharmacy, Yale University School of Medicine,

New Haven, CT, USA

${ }^{5}$ Abramson Cancer Center, University of

Pennsylvania,

Philadelphia, PA, USA

Corresponding Author: James J. Harrigan, MD, PharmD; Hospital of the University of Pennsylvania Philadelphia, PA, USA (e-mail: James.Harrigan@pennmedicine.upenn.edu).

Funding information This study was supported by the National Institutes of Health under the following award number: P3O CAO16520 (to RM).

\section{Compliance with Ethical Standards:}

Conflict of Interest: RM reports having served as a research consultant for Seattle Genetics and Astellas, unrelated to the submitted work. $R R$ reports personal fees from Johnson \& Johnson, Janssen, Portola, AstraZeneca, Pfizer, and Medicure, outside the submitted work. No other authors report disclosures. 


\section{REFERENCES}

1. The White House. Remarks by President Trump, Vice President Pence, and Members of the Coronavirus Task Force in Press Briefing. Published online March 19, 2020. Accessed April 20, 2020. https://www.whitehouse.gov/ briefings-statements/remarks-president-trump-vice-president-pencemembers-coronavirus-task-force-press-briefing-6/

2. Kim AHJ, Sparks JA, Liew JW, et al. A Rush to Judgment? Rapid Reporting and Dissemination of Results and Its Consequences Regarding the Use of Hydroxychloroquine for COVID-19. Ann Intern Med. Published online March 30, 2020. doi:https://doi.org/10.7326/M20-1223

3. Gautret $\mathbf{P}$, Lagier J-C, Parola $\mathbf{P}$, et al. Hydroxychloroquine and azithromycin as a treatment of COVID-19: results of an open-label nonrandomized clinical trial. Int $J$ Antimicrob Agents. Published online March 2020:105949. doi:https://doi.org/10.1016/j.ijantimicag.2020. 105949
4. Rome BN, Avorn J. Drug Evaluation during the Covid-19 Pandemic. $N$ Engl J Med. Published online April 14, 2020. doi:https://doi.org/10.1056/ NEJMp2009457

5. Borba MGS, Val FFA, Sampaio VS, et al. Effect of High vs Low Doses of Chloroquine Diphosphate as Adjunctive Therapy for Patients Hospitalized With Severe Acute Respiratory Syndrome Coronavirus 2 (SARS-CoV-2) Infection: A Randomized Clinical Trial. JAMA Netw Open. 2020;3(4.23):e208857. doi:https://doi.org/10.1001/jamanetworkopen. 2020.8857

6. Gabler E, Keller MH. Prescriptions Surged as Trump Praised Drugs in Coronavirus Fight. The New York Times. https://www.nytimes.com/2020/ 04/25/us/coronavirus-trump-chloroquine-hydroxychloroquine.html. Published April 25, 2020. Accessed May 8, 2020.

Publisher's Note: Springer Nature remains neutral with regard to jurisdictional claims in published maps and institutional affiliations. 